\title{
Teacher Position in Spurring Value Based Education in Early Learning in Nairobi County, Kenya: Addressing Support of Values in School Environment
}

\author{
Odundo P. Amollo ${ }^{1} \&$ Ganira K. Lilian ${ }^{1}$ \\ ${ }^{1}$ Department of Educational Communication and Technology, University of Nairobi, Nairobi, Kenya \\ Correspondence: Odundo P. Amollo, Department of Educational Communication and Technology, University of \\ Nairobi, P.O BOX 30197-00100, Nairobi, Kenya. E-mail: odundopaul@yahoo.com
}

Received: March 13, 2017

Accepted: April 10, 2017

Online Published: April 16, 2017

doi:10.5539/jel.v6n3p194

URL: http://doi.org/10.5539/jel.v6n3p194

\begin{abstract}
Value Based Education (VBE) is an essential element that impacts moral, ethical, cultural, social and spiritual ideals necessary for holistic development of children. Providing an education on values at an early age ensures that children are directed by these ideologies throughout life. Research indicates that children who adopt values at an early age are confident, competent, independent, and exhibit harmonious social interactions throughout life time. Conversely, increase in juvenile delinquency, disrespect, drug abuse, school dropout, and conflicts in schools creates crisis in contemporary society. In such circumstances, VBE assumes a distinctive role to school deterioration process by strengthening morals and ethics within the society. The study explored influence of preschool teachers in spurring VBE among preschool children in Nairobi County focusing on; self control honesty, fairness, compassion and trust. A survey design was adopted with a target population of 36 public preschools. Purposeful sampling technique was then used to obtain data from 36 preschool teachers though use of a questionnaire. The study established that though teachers inculcate values to children both consciously and unconsciously, there is no planned value education program established on formal learning. The study recommends; regular training of teachers on use of VBE to deliberately foster intercultural understanding, social cohesion and inclusion, as well as need for value oriented programmes focusing on effective pedagogy.
\end{abstract}

Keywords: compassion, fairness, honesty, self control, social cohesion, trust, value based education

\section{Introduction}

Value based education creates a strong learning environment that enhances academic attainment and develops social relationship skills that last throughout life time. Explicitly imparting values to children during early years provide a common ethical platform about interpersonal behaviour that provides capacity for acting responsibly. When VBE is inclusive in schools, a general attitude to work responsively is established among children, staff, and families, Rieser (2008). As a result, understanding of targeted values is achieved along with providing a positive focus for redirecting appropriate behaviour among children. However, in instances where VBE is weak and distorted, Klug (2014) opined that commitment to build a democratic nation becomes uncertain which in turn disrupts smooth running of the society. In this regard, the path towards a sustainable global civilization requires integration of knowledge, values, and education that addresses challenges facing modern world.

However, deterioration of human values is rampant in schools exhibited through burning of schools, indiscipline, violent crimes, drug peddling, school dropout and sexual abuse, Wachikwu and Ibegbunam (2012) and Turker et al. (2016). As a consequence, trend of decline in values create a threat to future development of the country, its continued existence, respect and authority. To address this concern, there is need to strengthen VBE in schools with an aim of helping children discover unique potential rather than entirely concentrating on acquisition of knowledge and skills competitive in the job market. In this context, teachers should train children in positive behaviour such as self control, honesty, fairness, compassion and trust with an intention of visualizing the future. It is based on this background that the study seeks to examine the support of teachers in inculcating VBE among preschool children in Nairobi County. 


\subsection{Teachers Foster Value Based Education}

Teachers are key persons in creating value-based learning environment that foster positive relationships to children with an aim of producing responsible and effective citizens. In a study on perceived social support and achievement of adolescents, Ahmed et al. (2008) observed that teachers with positive attitudes are more likely to respond favourably to developmentally appropriate practices while those with low efficacy find it difficult to maintain discipline among learners. In this regard, nurturing values to children require structured child-centred practices that enhance positive behaviour such as self control, honesty, fairness, compassion, and trust among children. Similarly, Brownlee, Boulto, and Berthelsen (2008) pointed out that, teachers who reflect on activities that focus on what is right and wrong, have children who demonstrate self control, compassion and learn how to care for own belongings. Based on these arguments, VBE ought to be strengthened through appropriate mentorship skills as an essential paradigm shift considered as an intervention for ethical decline in society.

Given that teachers pass values to children both consciously and unconsciously through conduct in and out of class, Reinders, and Balcikanli (2011) emphasized the need for a careful planned VBE programme focusing on an interactive, integrative and knowledge based approach. Hence, employing value specific teaching and learning resources is crucial for mentoring children into productive future citizens. In support of this view, Turker et al. (2016) found out that when a sense of security and knowledge of right and wrong is reinforced, the child learns honesty, and how to care for others, experience harmonious relationships and avoids conflict. Consequently, modelling positive values, integrating value education in all curricular and fostering value awareness among preschool children is vital for supporting VBE.

\subsection{Children's Behaviour and Value Based Education}

The behaviour preschool children exhibit in relation to social skill development and schooling is a strong predictor of adult conduct. Children who grow up with positive values are confident, have respect as well as self esteem, which translates into appropriate behaviour. Besides being a source of knowledge, Reinders and Balcikanli (2011) stressed that an effective teacher works towards fostering desirable characteristics of learners towards honesty, responsibility, etiquette, self-esteem and cooperation with others. By implication, appropriate characteristics support positive behaviour among children and create opportunities for informed and responsible citizens. In addition, Larisa et al. (2016) revealed that learners who feel valued and respected have self esteem, exhibit a sense of self-worth, take an active role in group, have a feeling of empathy for others, and resolve differences harmoniously. Thus a positive inclusive learning environment where children are receptive, coupled with nurturing adults is crucial for achieving positive behaviour.

Modelling positive attitudes and appropriate language helps children to learn socially acceptable behaviour and interacting with others. In addition, Bolarin (2009) indicated that teachers who support early social development have children who make friends easily, communicate with different audiences, settle into school and understand how to behave appropriately in different situations. Thus, demonstrating Positive behaviour includes, communicating openly and honestly, showing awareness as responsible citizens, as well as articulating values in and out of school. Further analysis by Brock (2012) showed that when teachers adopt a positive active approach in class, children reduce challenging behaviours. As a result addressing values in developmentally appropriate approaches enable children to communicate openly, have confidence, be receptive to learning as well as understand values and consequences of own actions.

\subsection{Significance of Value Based Education}

With deliberate and thoughtful emphasis on VBE, schools are likely to become communities where virtues such as self-control, honesty, kindness, compassion, and trust are celebrated. Indeed, schools that emphasize on VBE encourage principles of self-reliant, self discipline and contentment, hence responsible learners. When appropriate values are inculcated, Thompson (2011) opined that children experience harmonious social interaction and independent learning which translates into creating a sustainable social environment. In this regard, VBE helps learners develop dispositions for flourishing intellectually, personally and socially. In addition, Weiland and Yoshikawa (2013) found out that children who acquire positive values develop empathy which transforms into responsible, focused and cooperative classes equipped for better learning and social outcomes. Based on this observation, VBE allows children to become socially adjusted, well-mannered and capable of becoming competent adults able to decide between right and wrong.

In a study on impacts of insecurity on school attendance and dropout among slum children in Nairobi County, Mudege, Machel and Ngetich (2013), showed that by acquiring values, children demonstrate awareness of themselves as constructive members of society, through communicating openly and honestly with others. Hence, 
teachers have the responsibility of shaping lives of children by inculcating appropriate values for behaviour transformation and ethical orientation. Furthermore, Macfarlane (2014) found out that in an environment where VBE is explicit, learners become industrious while the school assumes a peaceful ambiance in addition to self-regulated behaviour. Based on this argument, there is need for imparting proper values among children in order to achieve social order within the society.

\subsection{Institutional Support for Value Based Education}

School being an agent of socialization and transformation is expected to assist the society in its quest for responsible citizens. In this regard, UNESCO (2004) emphasized that core values instilled in learners should be translated from one culture to another with the aim of producing children who are happy with themselves and others. Achieving a harmonious society requires a new paradigm shift in management of schools where children are exposed to qualitative education and acquire values that will enable society to function effectively. In support of this argument, Odhiambo (2010) opined that strengthening of VBE in schools provides an enabling platform for sustained development and realization of vision 2030. Hence the role of the school entails equipping children with positive values that enhance responsibility and develops productive members of the society.

Achievement of sustainable development can only be attained if schools support value system that sustain decision making and problem solving. Further still, Weiland and Yoshikawa (2013) stressed that having an understood agreement on values enables schools to experience a peaceful and calm environment, where improved learner-teacher relationships are attained. This may include effective school policies, common value language and value focused pedagogy. When value creation is realized, schools are likely to build character that produces behaviour beneficial to the individual and the society which translate into preservation of a democratic society.

\section{Statement of the Problem}

Value based education aids in promoting social and natural integration, awakens curiosity, development of proper interests, attitudes and capacity to think and judge others. Providing an education on values at an early age ensures that children are guided by appropriate ideologies throughout life. Given that educators are aware of cultural crisis within the society, Almon (2010) emphasized the need to promote ethical development in schools where a set of values are developed. When values are formal, accepted and appreciated within the school culture, it becomes crucial for schools to ensure that staffs as well as learners are beneficiaries and recipients in respectful and caring interactions.

However, analysis by Mudege, Machel and Ngetich (2013) showed an increase in juvenile delinquency, drug abuse, school dropout, and conflicts in schools, which creates crisis in contemporary society. Additionally, report by Teachers' Service Commission, and Ministry of education, on July $15^{\text {th }} 2016$ indicated burning of over 100 schools in many parts of the country within a period of two months as an example of moral decay within society. Trends of decline in human values jeopardize efforts directed at stimulating future path for development of the country, its survival, respect and authority. Hence, existence and sustenance of VBE in all curricular is likely to amount to a potent force towards realization of effective citizenry. Based on this realization, this study explored the role of teachers in developing VBE among preschool children.

\section{Purpose and Objective}

The purpose of the study is to determine the role played by teachers in inculcating VBE to preschool children. The objective is to examine appropriateness of value based education in preschool setting.

\section{Theoretical Framework}

The study is conceptualized around moral development theory by Kohlberg (1978). Moral development involves children learning how to tell the difference between right and wrong, and use this knowledge to arrive at appropriate decisions when confronted with complicated choices and to have independence to act in the right way. Consequently, Smith, Cowie and Blades (2003) argued that children do not operate in isolation but by interacting with more knowledgeable others including adults, older peers, or teachers, implying that interpersonal experience with significant others combine to influence moral development.

Children should to be guided to follow certain rules of etiquette while eating, to use the birth room appropriately, and express feelings of anger and frustration without hurting others. In this context, individual judgement is based on self-chosen principles and moral reasoning. When teachers focus on sense of caring and responsibility, children understand that other people have different rules concerning morality. The child then develops a sense of reciprocity and fairness that guides throughout entire life time. As a result the school is likely to experience 
enhanced quality teaching, child-teacher relationship and improved communication among children. Thus, helping children to grow in this perspective is the goal of value based education.

\section{Conceptual Framework}

The conceptual framework is grounded in the belief equipping children with VBE generates a culture of responsive and productive members of the society. Without values, individuals make decisions that do not benefit the society. It is therefore the responsibility of teachers to analyse and consider appropriate tasks needed for children to effectively develop values. Children understanding of their world and age appropriate activities and explicit instruction are crucial to learning since values are essence of healthy relationships and essential for conduct and preservation of a democratic society. The role of the teacher entails, modelling positive values, integrating VBE in all aspects of curricular and fostering value awareness among children. When this is attained, children are likely to demonstrate effective communication skills, become confident, and receptive to learning as well as experience a harmonious social interaction and independent learning. Hence VBE can be implemented through various methods including; adopting a school policy, establishing a common language, and developing pedagogies that are values-focused and learner centred. When this is accomplished there is a likelihood of the school to experience enhanced quality teaching, child-teacher relationship and improved communication.

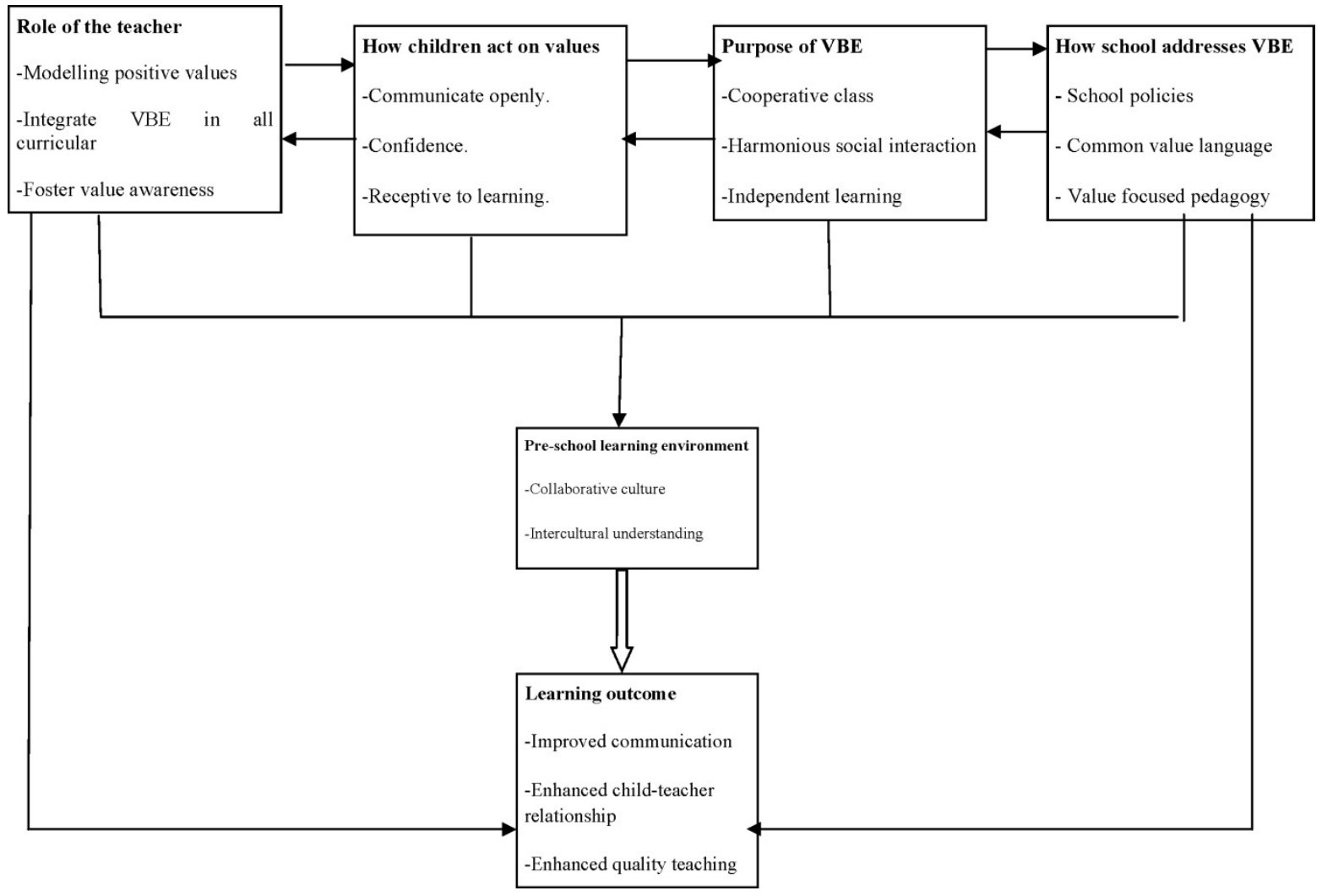

Figure 1. Conceptual framework. Teacher support for value based education

\section{Data and Methodology}

Survey design was used to provide information on how teachers address the concept of value based education. Orodho and Kombo (2002) define survey method as a descriptive research method of collecting information by interviewing or administering a questionnaire to a sample of individuals or can be used when gathering data about opinions or attitudes of people. Choice of descriptive survey design was based on the fact that the study was interested in the state of affairs existing in the field and no variable was manipulated. The study applied simple random sampling to identify 36 public preschools. Purposive sampling technique was then used to pick 1 preschool teacher from every school. In total, 36 teachers participated in the study. According to Welman and Kruger (1999) Purposive sampling is considered as the most important kind of non-probability in identifying 
primary participants. Data for achieving objectives of this study was obtained from primary sources though use of a questionnaire. A questionnaire is used to gather information over a large scale Kombo and Tromp (2006). In addition, use of a questionnaire enabled respondents to feel free to note down their responses without anxiety. Data arising from responses using likert scale were calculated in percentages, analysed thematically and presented using tables.

\section{Study Findings}

\subsection{Respondents Composition by Age, Experience and Academic Qualification}

Academic qualifications and professional orientation are indicators of one's potential towards problem solving and productivity. This is based on the understanding that responsibility defined on professional orientation and academic achievement contribute towards set goals. The study sought to find out age, work experience and academic qualification of the respondents. Findings are summarized in Table 1.

Table 1. Characteristics of the respondents

\begin{tabular}{lllllllll}
\hline Age & F & $\mathbf{\%}$ & Experience (Yrs) & $\mathbf{F}$ & $\mathbf{\%}$ & Academic qualification & F & $\%$ \\
\hline$<30$ & 2 & 5.6 & $5-10 \mathrm{yrs}$ & 2 & 5.6 & Certificate in E.C.E & 6 & 16.7 \\
$31-40$ & 9 & 25 & $11-15 \mathrm{yrs}$ & 7 & 19.4 & Diploma in E.C.E & 29 & 80.6 \\
$31-40$ & 17 & 47.2 & $16-20 \mathrm{yrs}$ & 11 & 30.6 & Bachelor in E.C.E & 1 & 2.7 \\
$>50$ & 8 & 22.2 & $>20 \mathrm{yrs}$ & 16 & 44.4 & Masters in E.C.E & 0 & 0 \\
Total & $\mathbf{3 6}$ & $\mathbf{1 0 0 \%}$ & Total & $\mathbf{3 6}$ & $\mathbf{1 0 0 \%}$ & Total & $\mathbf{3 6}$ & $\mathbf{1 0 0 \%}$ \\
\hline
\end{tabular}

Results in Table 1 showed that out of 36 respondents 2 (5.6\%) were below age 30, while $9(25 \%)$ fell in the age bracket of 31-40. Majority of the respondents $17(47.2 \%)$ were between ages 41-50 while age 50, $8(22.2 \%)$ and above were the least in the survey. This is an indication that most of the respondents were capable of steering growth and development in the preschool sub sector.

Data on work experience revealed that $2(5.6 \%)$ respondents had between 5-10 years, 7 (19.4\%) had 11-15 years, $11(30.6 \%)$ had 16-20 years. Given that majority of the teachers, $16(44.4 \%)$ had an experience of 20 years and above was an indication they are capable of implementing VBE among preschoolers. Findings on academic qualification revealed that $6(16.7 \%)$ out of 36 respondents were certificate holders, $29(80.6 \%)$ were diploma holders while $1(1.27 \%)$ had degree. Based on this analysis, Barret and Green (2009) noted that specialists with high educational qualification are known to possess appropriate knowledge, skills, values and attitudes indicating ability in implementing appropriate practices that influence achievement of learners.

\subsection{Role of the Teacher in Value Based Education}

Teachers have the responsibility of shaping the life of children by imparting appropriate values. The study therefore sought to find out what role teachers play in spurring VBE. The findings are shown in Table 2.

Table 2. Role of the teacher in value based education

\begin{tabular}{|c|c|c|c|c|c|}
\hline Item & $\begin{array}{l}\text { Strongly } \\
\text { agree }\end{array}$ & Agree & Neutral & Disagree & $\begin{array}{l}\text { Strongly } \\
\text { disagree }\end{array}$ \\
\hline I am conscious of my role in modelling values to children. & $78 \%$ & $11 \%$ & $5 \%$ & $5 \%$ & $1 \%$ \\
\hline I am confident with mentoring values to children. & $68 \%$ & $23 \%$ & $4 \%$ & $4 \%$ & $1 \%$ \\
\hline I integrate values into all aspects of learning. & $39 \%$ & $49 \%$ & $6 \%$ & $3 \%$ & $3 \%$ \\
\hline I foster value awareness to children in all curricular. & $43 \%$ & $45 \%$ & $4 \%$ & $6 \%$ & $2 \%$ \\
\hline I am inspired by the insights children have into own and others' values. & $54 \%$ & $29 \%$ & $7 \%$ & $7 \%$ & $3 \%$ \\
\hline I have confidence in imparting values to children. & $57 \%$ & $40 \%$ & $1 \%$ & $1 \%$ & $1 \%$ \\
\hline I use specific values education resources in my teaching. & $39 \%$ & $47 \%$ & $4 \%$ & $6 \%$ & $4 \%$ \\
\hline I need more professional development about values education. & $80 \%$ & $15 \%$ & $2 \%$ & $2 \%$ & $1 \%$ \\
\hline I provide opportunities for children to explore and articulate their values. & $66 \%$ & $26 \%$ & $2 \%$ & $4 \%$ & $2 \%$ \\
\hline
\end{tabular}


According to the study findings in Table 2 out of $100 \%, 78 \%$ of the respondents strongly agreed they were conscious about modelling positive values to children. This would positively provide opportunities for children to develop personal values and attribute. On the contrally, $1 \%$ strongly disagreed. In respect to whether teachers had confidence in mentoring values, $68 \%$ strongly agreed. This finding implies that most of the teachers are aware of the need for values, although $1 \%$ strongly disagreed. When asked whether they integrate values education into all aspects of learning 39\% strongly agreed. This is of great concern since value education is vital in every aspect of the curriculum to enable children cope with reality of modern world. Conversely, $3 \%$ strongly disagreed, an indication that some teachers are not concerned about the need for value education. Further still, $43 \%$ strongly agreed that they developed value awareness in all curricular while $2 \%$ strongly disagreed.

A positive respond was attained when $54 \%$ strongly agreed they are inspired by insights children have into own and peers values, however, $3 \%$ strongly disagreed. It was also evident from the study findings that majority of the teachers, $57 \%$ had confidence in imparting values to children. This implies that children benefit from value education and should be able to demonstrate positive ethics in and out of class, even though $1 \%$ strongly disagreed. In supporting this finding, Weiland and Yoshikawa (2013) emphasized that children who acquire positive values develop empathy which translates into responsible, focused and cooperative classes equipped for better learning and social outcomes. Whether teachers used specific values education resources in teaching, 39\% strongly agreed while $4 \%$ strongly disagreed, implying that though values are taught resources still remain inadequate. Majority of the teachers, $80 \%$ strongly agreed they needed professional development for effective implementation of VBE. However, 1\% strongly disagreed. Further still, 66\% strongly agreed they provided opportunities for children to explore and articulate their values while $2 \%$ strongly disagreed. It is evident from these findings that there exist inconsistencies in the manner in which teachers handle value based education besides its significance in developing informed and responsible children.

\subsection{How Children Act on Values}

Value based education has the potential to impact positively on the total education resulting in teacher-learner relationship and class ethos. The study examined how children act on their values and the results are presented in Table 3.

Table 3. How children demonstrate values

\begin{tabular}{|c|c|c|c|c|c|}
\hline Item & Always & Often & Sometimes & Never & Uncertain \\
\hline Children demonstrate positive behaviour to others within the school community. & $19 \%$ & $72 \%$ & $6 \%$ & $1 \%$ & $2 \%$ \\
\hline Children are aware of their responsibility in school. & $40 \%$ & $6 \%$ & $17 \%$ & $2 \%$ & 35 \\
\hline Children are receptive to learning about values. & $39 \%$ & $27 \%$ & 29 & $3 \%$ & $2 \%$ \\
\hline Children are enthusiastic about putting values into action. & $69 \%$ & $20 \%$ & $9 \%$ & $1 \%$ & $1 \%$ \\
\hline Children can communicate openly and honestly with others about values. & $67 \%$ & $19 \%$ & $11 \% \%$ & $1 \%$ & $2 \%$ \\
\hline Children look to role models within the school to learn about values. & $31 \%$ & $55 \%$ & $10 \%$ & $1 \%$ & $3 \%$ \\
\hline Children feel confident to stand by their values. & $40 \%$ & $40 \%$ & $18 \%$ & $1 \%$ & $1 \%$ \\
\hline Children can articulate positive values. & $39 \%$ & $40 \%$ & $18 \%$ & $1 \%$ & $2 \%$ \\
\hline Children understand how values relate to their actions. & $41 \%$ & $39 \%$ & $17 \%$ & $1 \%$ & $3 \%$ \\
\hline
\end{tabular}

Study findings from Table 3 showed that out of 36 respondents, 19\% put forward that children demonstrate positive behaviour to others in the community while $2 \%$ were uncertain due to children having inadequate exposure to values education. This may be the reason why some children do not demonstrate positive behaviour regularly. A notable finding was that $40 \%$ indicated that children showed awareness of themselves as constructive members of the community while $35 \%$ were uncertain. This finding corroborates with an earlier finding of Machel and Ngetich (2013) that children show awareness of themselves as constructive members of the society, through communicating openly and honestly with others. Even though school is expected to take full responsibility of ensuring that children develop positive values during preschool period, this was not the case given that $39 \%$ indicated that children are receptive to learning about values while $2 \%$ were uncertain. However, on aggregate a large number of teachers, $69 \%$ showed that children are enthusiastic about putting values into action while $1 \%$ was uncertain. This could be due to an assumption of some teachers that value education is the responsibility of parents. Further still a large number, $67 \%$ reported that children always communicate openly and honestly with others about values although $2 \%$ were uncertain. 
Concerning whether teachers model values that children can emulate, $31 \%$ indicated that children always look to role models within the school to learn about values while 3\% were uncertain. It was therefore clear that though some teachers have concern about the value children imitated, others were not apprehensive. When asked whether children always respected the value of others, $40 \%$ responded in the affirmative while $1 \%$ was uncertain. This finding further reveals inadequacy on part of the teachers in developing values to children. One aspect of value education is ability to stand for the truth. In regard to this, $39 \%$ showed that children always feel confident to stand by their values while $1 \%$ was uncertain. Similarly, 39\% showed that children always articulate their values while $2 \%$ were uncertain. Even though $41 \%$ showed that children always understand how values relate to their actions there was at least $3 \%$ that were uncertain. It is evident that discrepancy in the way children communicative own values is a clear indication of inadequacy in the development of value education in schools.

\subsection{How the School Addresses Value Education}

Society looks to schools to develop values, knowledge and skills that address contemporary challenges and create an appropriate society. The study examined how schools contribute to the lives of children by providing opportunities to develop personal value attributes. Findings are indicated in Table 4.

Table 4. How the school addresses value based education

\begin{tabular}{|c|c|c|c|c|c|}
\hline Item & $\begin{array}{l}\text { Strongly } \\
\text { agree }\end{array}$ & Agree & Neutral & Disagree & $\begin{array}{l}\text { Strongly } \\
\text { disagree }\end{array}$ \\
\hline There is an explicit school approach to value based education. & $35 \%$ & $57 \%$ & $4 \%$ & $2 \%$ & $2 \%$ \\
\hline Values are expressed explicitly thought out the school. & $19 \%$ & $44 \%$ & $10 \%$ & $6 \%$ & $21 \%$ \\
\hline There is an understood agreement on the value the school fosters. & $21 \%$ & $38 \%$ & $21 \%$ & $8 \%$ & $9 \%$ \\
\hline Parents are actively engaged in supporting the values education approach of the school. & $19 \%$ & $54 \%$ & $17 \%$ & $8 \%$ & $7 \%$ \\
\hline Values are taught as part of the school curriculum. & $11 \%$ & $19 \%$ & $4 \%$ & $29 \%$ & $37 \%$ \\
\hline Values frame all school policies. & $10 \%$ & $21 \%$ & $13 \%$ & $30 \%$ & $26 \%$ \\
\hline Value based education is used to help build positive relationships. & $54 \%$ & $33 \%$ & $7 \%$ & $4 \%$ & $2 \%$ \\
\hline Values are taught to encourage understanding across cultures. & $69 \%$ & $24 \%$ & $5 \%$ & $1 \%$ & $1 \%$ \\
\hline There is a common values language used across the school. & $27 \%$ & $31 \%$ & $11 \%$ & $14 \%$ & $17 \%$ \\
\hline Children are given opportunities to act on their value beyond the classroom. & $44 \%$ & $40 \%$ & $7 \%$ & $3 \%$ & $2 \%$ \\
\hline Values perspectives are used to explore confronting issues in the class. & $52 \%$ & $40 \%$ & $4 \%$ & $3 \%$ & $1 \%$ \\
\hline
\end{tabular}

With intentional and thoughtful emphasis on value based education, schools can become communities in which virtues such as self-control, honesty, fairness, compassion, and trust are taught and celebrated. Findings from Table 4 revealed that, out of 36 respondents $35 \%$ strongly agreed that there is an explicit approach to value education while $2 \%$ strongly disagreed. This finding shows that value education is inadequate at early learning period. Though children become empowered to take responsibility through value education, only $19 \%$ strongly agreed that values are expressed throughout the school while $21 \%$ strongly disagreed. This could be the reason why many children complete schooling without the required values for surviving in the modern world. When asked whether there is an understood agreement on the values the school fosters $21 \%$ strongly agreed while $9 \%$ strongly disagreed. This finding contradicts the work of Weiland and Yoshikawa (2013) who suggested that schools should have an understood agreement on values to foster. Additionally, $19 \%$ strongly agreed that parents are actively engaged in supporting value education while $7 \%$ strongly disagreed, yet inadequate parental involvement could jeopardize gains made in developing responsible children. Although Aloni (2003) noted that values should be taught as part of the school curriculum, $11 \%$ strongly agreed while $37 \%$ strongly disagreed.

Further analysis showed that $10 \%$ strongly agreed that values frame all school policies while $26 \%$ strongly disagreed. This finding implies that there is no agreed policy, nor planned curriculum on how value education should be handled at preschool education. In an outstanding finding, 54\% strongly agreed that value based education is used to help build positive relationships. However, $2 \%$ strongly disagreed. Similarly, $61 \%$ strongly agreed that values are taught to encourage understanding across cultures while $1 \%$ strongly disagreed. Besides, $27 \%$ strongly agreed that there is a common values language used across the school while $17 \%$ strongly disagreed. This implies that there exist challenges in handling values education. This indirectly raises the issue for deterioration of values within the society. In addition, $44 \%$ strongly agreed that children are given opportunities to act out values beyond the classroom while $2 \%$ strongly disagreed. Further still, $52 \%$ strongly agreed that values perspectives are used to explore complex issues while $1 \%$ strongly disagreed. This situation therefore creates a challenge in realization of sustainable development in society. 


\subsection{Purpose of Value Based Education}

An important consequence of value based education is a settled school which enhances quality teaching and enables teachers to raise expectations of learner performance. The study explored the need for value based education in schools. The results are presented in Table 5.

Table 5. Purpose of value based education

\begin{tabular}{|c|c|c|c|c|c|}
\hline Item & $\begin{array}{l}\text { Strongly } \\
\text { agree }\end{array}$ & Agree & Neutral & Disagree & $\begin{array}{l}\text { Strongly } \\
\text { disagree }\end{array}$ \\
\hline Society benefits from values education that takes place in the school. & $49 \%$ & $47 \%$ & $1 \%$ & $1 \%$ & NIL \\
\hline Value based education addresses personal, local and global contexts. & 84 & $15 \%$ & $1 \%$ & NIL & NIL \\
\hline The school models the values they want children to enact. & $86 \%$ & $12 \%$ & $2 \%$ & NIL & NIL \\
\hline $\begin{array}{l}\text { The school offers children authentic opportunities for personal and social action } \\
\text { based on values. }\end{array}$ & $81 \%$ & $15 \%$ & $2 \%$ & $1 \%$ & $1 \%$ \\
\hline The school imparts values that promote Kenya's democratic way of life. & $94 \%$ & $6 \%$ & NIL & NIL & NIL \\
\hline $\begin{array}{l}\text { In the school, value based education is linked to participation in the local } \\
\text { community. }\end{array}$ & 92 & $5 \%$ & $1 \%$ & $1 \%$ & $1 \%$ \\
\hline The school fosters values that can help children cope with difficulty of modern life. & 85 & $12 \%$ & $1 \%$ & $1 \%$ & $1 \%$ \\
\hline
\end{tabular}

Results from Table 5 revealed that out of 36 respondents $49 \%$ strongly agreed that society benefits from values education. In addition, $84 \%$ strongly agreed that value education should address personal local and global context, while, $86 \%$ strongly agreed that schools require to model values they want children to enact. Further still, $81 \%$ strongly agreed that schools should offer opportunities for personal and social action based on values while $1 \%$ strongly disagreed. A notable finding was that $94 \%$ strongly agreed that schools need to teach values that promote Kenya's democratic way of life. This finding corroborate with the work of Weiland and Yoshikawa (2013) who stressed that schools should have an understood agreement on values in order to promote a peaceful and calm environment, where improved learner-teacher relationships are attained. Additionally, $92 \%$ strongly agreed that value based education should be linked to local community while $1 \%$ strongly disagreed. Lastly, $85 \%$ strongly agreed that value based education can help children cope with difficulties of modern society while $1 \%$ strongly disagreed.

\section{Conclusion}

The study established that there exist inconsistencies in the manner in which teachers handle value based education besides its significance in developing informed and responsible children. Value based education seemed to be taken for granted by teachers since there is no agreed policy, nor planned curriculum on how it should be handled at preschool level. These points to the reason why many children complete schooling without required values for surviving in the modern world. The challenges in handling values education indirectly raise the issue for deterioration of values within the society. Further findings showed inadequacy of value education and most schools lack an understood agreement on the nature of values to foster. Schools should therefore contribute to lives of children by providing opportunities to develop personal value attributes.

\section{Recommendations}

The study makes the following recommendations:

- There is increasing demand from schools in respect to formulation of acceptable values for children to absorb and live with. In this regard, the ministry of education should introduce a national policy on values education as an instrument for behavioural transformation and ethical orientation.

- There is rapid deterioration of human values within the society. To address this challenge, schools should develop relevant and engaging values approach connected to local and global contexts.

- Schools should establish and consistently use a common and shared values language and explicitly teach values for children to understand the meaning and how they are lived for social cohesion.

- Teachers should improve professional practice and modelling of appropriate class value based activities as well as including other stake holders in developing value based education.

- Schools should have a critical approach to values education as well as the need for qualified professional knowledge and skills in value education. 


\section{References}

Almon, J. (2010). The vital role of plan in early childhood. Waldorf Early Childhood Association of North America. Retrieved from http://www.waldorfearlychildhood.org/article.asp?id=5

Aspin, D. (2002). An Ontology of Values and the Humanisation of Education. In S. Pascoe (Ed.), Values in Education. Australian College of Educators, ACT.

Barrett, D., \& Green, K. (2009). Pedagogical content knowledge as a foundation for an inter-disciplinary graduate program. Science Educator, 18(1).

Klug, J., Krause, N., Schober, B., Finsterwald, M., \& Spiel, C. (2014). How do teachers promote their students' lifelong learning in class? Development and first application of the LLL I nterview. Teach Teach Educ, 37, 119-129. https://doi.org/10.1016/j.tate.2013.09.004

Kohlberg, L. (1978). The cognitive-developmental approach to moral education. In P. Scharf (Ed.), Readings in moral education (pp. 36-51). Minneapolis: Winston Press.

Kombo, D. K., \& Tromp D. L. A. (2006). Proposal and Thesis Writing: An Introduction. Pauline's publication Africa.

Larisa, P. L., \& Natalia, V. Z. (2016). Personal and Professional Responsibilities of Students: Pychological and Pedagogical Factors of Real Opportunities (Vol. 11, No. 5, pp. 1351-1358).

Macfarlane, B. (2014). Teaching, integrity and the development of professional responsibility (p. 72). Professional responsibility: New Horozons of Praxis.

Mudege, N., Machel, G., \& Ngetich, P. (2013). How Insecurity Impacts on School Attendance and School Dropout among Slum Children in Nairobi. Journal of Conflict and Violence, 2(1), 98-112.

Odhiambo, D. (2010). Task force on re-alignment of education to the Constitution 2010 and Vision 2030 and beyond. The Government of Kenya.

Rean, A. A. (2013). Psychology of Personality (p. 325). St. Petersburg: Publishing House.

Reindres, H., \& Balcikanli, C. (2011). Learning to foster autonomy: The role of teacher education materials. Studies in Self-Access Learning Journal, 2(1), 15-25.

Rieser, R. (2008). Implementing Inclusive Education. London, Commonwealth secretariat.

Smith, P. K., Cowie, H., \& Blades, M. (2003). Understanding Children's Development (4th ed.). Blackwell Publishing, Oxford.

Thompson, M. (2011). Developing moral values in children: Observation from preschool. Ife Psychology, 19(2), 394-411. https://doi.org/10.4314/ifep.v19i2.69584

Turker, D., Vural, C. A., \& Idowu, S. O. (2016). Social Responsibility Education Across Europe (p. 354). London: Springer. https://doi.org/10.1007/978-3-319-26716-6

UNESCO. (2004). Embracing Diversity: Toolkit for Creating Inclusive, Learning-Friendly Environments. Paris, UNESCO. Retrieved November 4, 2015, from http://unesdoc.unesco.org/images/0013/001375/137522e.pdf

Wachikwu, T., \& Ibegbunam, J. O. (2012). Psychosocial factors influencing antisocial behaviour among secondary students in Obio-Akpor local area of river state. International Journal of Education Development, 2(1), 104-113.

Weiland, C., \& Yoshikawa, H. (2013). Impacts of a prekindergarten program on children's mathematics, language, literacy, executive function, and emotional skills. Child Development, 84(6), 2112-2130. https://doi.org/10.1111/cdev.12099

Welman, J. C., \& Kruger, S. J. (1999). Research methodology for the business and administrative sciences. Johannesburg, South Africa: International Thompson.

Wood, J. (2007). Parallel services delivery in a fragile state-an opportunity for coordinating capacity building in Haiti. Retrieved March 27, 2008, from www.capacity.org/en/Journal/Practice-Reports/Paralel-Services-delivery-in-a-fragile-state 


\section{Copyrights}

Copyright for this article is retained by the author(s), with first publication rights granted to the journal.

This is an open-access article distributed under the terms and conditions of the Creative Commons Attribution license (http://creativecommons.org/licenses/by/4.0/). 